\title{
Avaliação do Sistema de Treinamento e Desenvolvimento em Empresas Paulistas de Médio e Grande Porte
}

\author{
Keli Cristina de Lara Campos ${ }^{12}$ \\ Ana Lúcia Jancovic Barduchi \\ Daniela Giallucca Marques \\ Kátia Perez Ramos \\ Ligia Angeli Dias dos Santos \\ Tatiana Janine Becker \\ Universidade São Francisco, Itatiba/SP
}

\begin{abstract}
Resumo
Atualmente a aprendizagem no trabalho vem sendo cada vez mais relevante, fato que leva ao investimento em treinamento. O presente trabalho objetivou avaliar este sistema e para tanto participaram 300 empresas do Estado de São Paulo com mais de 100 funcionários. Os instrumentos, enviados por correio, foram devolvidos em até 60 dias. Os resultados indicam pouco controle dos gastos em Treinamento, visto que $44,67 \%$ das empresas não têm conhecimento do valor investido nesta área. 70,33\% das organizações relatam analisar sistematicamente as necessidades de Treinamento, enquanto 73,67\% controlam a eficiência do mesmo. A maneira de controle mais utilizada é o feedback informal (50,33\%). As futuras necessidades de Treinamento se encontram nas áreas de administração de negócios e estratégia $(12,22 \%)$ e de gerenciamento de pessoal e supervisão $(11,78 \%)$. Apesar de muitas empresas detectarem a necessidade da aprendizagem de novas habilidades, os recursos investidos em Treinamento ainda são pouco sistematizados e requerem maior atenção.

Palavras-chave: Recursos humanos; treinamento e desenvolvimento; empresas paulistas.
\end{abstract}

\section{Assesment of the Training and Development System in Medium and Large Companies from the State of São Paulo}

\begin{abstract}
Nowadays work learning is becoming more and more relevant, a fact that leads to training investiments. This research aimed to evaluate this system and to do so 300 companies from Sao Paulo state with more than 100 employees were investigated. The questionnaires have been sent by mail and returned in 60 days, the maximum. The results show little control in training expenses, since $44,67 \%$ of the companies do not know the amount spent in training; $70,33 \%$ of the companies confirm that they systematically analyze the training needs, while $73,67 \%$ control the efficiency of training. The most used way of controlling training is informal feedback $(50,33 \%)$. Future needs of training are located in the business administration and strategy areas, $(12,22 \%)$, personnel management and supervision (11,78\%). Although many companies have recognized the need of learning new abilities, the resources invested in training are not enough systematized enough, then requesting more attention.

Keywords: Human resources; system of training and development; companies from the state of São Paulo.
\end{abstract}

Para Chiavenato (1996), as empresas são fundamentalmente constituídas de inteligência, algo que apenas as pessoas possuem, e o capital somente será bem aplicado quando for inteligentemente investido e administrado. Para tanto, a administração de recursos humanos toma-se prioritária em relação à administração do capital ou a qualquer outro recurso empresarial, como máquinas, equipamentos, instalações, clientes, etc. As empresas bemsucedidas se deram conta disso e voltaram-se para seus funcionários como os elementos alavancadores de resultados dentro da organização, descobrindo que todo investimento em pessoas, quando bem feito, provoca retornos garantidos à empresa. Chiavenato lembra que o investimento gradativo no

${ }^{1}$ Apoio financeiro da FAPESP e Universidade São Francisco. Agradecimentos às empresas que participaram deste estudo.

${ }^{2}$ Endereço para correspondência:Universidade São Francisco, Rua Alexandre Rodrigues Barbosa, 45, Itatiba, SP, 13251 900. Fone: (11) 78048103. aperfeiçoamento e treinamento de pessoal é o principal desafio de Recursos Humanos (RH).

Todas as políticas de recursos humanos, inclusive as de treinamento, estão subordinadas à filosofia empresarial e devem ser dotadas da necessária flexibilidade, adaptando-se aos objetivos organizacionais. Enquanto a filosofia da empresa é mais duradoura e estável, as políticas de recursos humanos são mais mutáveis e dependem, dentre outros fatores, das reações do mercado, da influência do Estado e das estabilidades política, econômica e social do país. Estes e outros aspectos relacionados ao plano estratégico da empresa constituem um quadro de referência para o levantamento e fixação de metas de recursos humanos, particularmente, de treinamento e desenvolvimento de pessoal (Carvalho \& Nascimento, 1997).

Os principais objetivos do treinamento e desenvolvimento de pessoal refletem as mudanças econômicas, tecnológicas e 
sociais do mercado onde a empresa atua, exigindo a efetivação de planos de formação profissional que sejam flexíveis, dinâmicos e atualizados (Carvalho \& Nascimento, 1997).

Neste sentido, Salas e Cannon-Bowers (2001), ao revisarem as pesquisas sobre treinamento na Annual Review of Psychology, constataram que essa área de atuação tem progredido significativamente, tanto em termos da ciência, quanto em prática de treinamento. Além disso, as recentes revisões têm documentado a existência de teorias relacionadas a treinamento e um grande aumento das pesquisas empíricas, especialmente nos últimos 10 anos.

Atualmente o treinamento vem sendo utilizado pelas empresas com o objetivo geral de desenvolver pessoas, tanto na aprendizagem de novas habilidades quanto na ampliação daquelas já existentes, uma vez que as pressões sócio-culturais, tecnológicas, econômicas e políticas direcionam as organizações contemporâneas a se adaptarem às exigências que o mercado impõe, focando mais intensamente seu capital humano.

Garay (1997) relata que existem diferenças significativas entre qualificação e treinamento. A primeira poderia ser definida com base no tempo de experiência do trabalhador e é adquirida de forma individual ou coletiva, tendo em vista as exigências do posto de trabalho; já a segunda seria um instrumento de conhecimento, favorecendo o saber tanto teórico, quanto prático dos trabalhadores.

Como resumem Carvalho e Nascimento (1997), o treinamento é um processo que auxilia o empregado a adquirir eficiência no seu trabalho presente ou futuro, através de apropriados hábitos de pensamento, ação, habilidades, conhecimentos e atitudes. Para Magalhães e Borges-Andrade (2001), o treinamento pode ser visto como um instrumento administrativo de vital importância para o aumento da produtividade do trabalho, e também como um fator de auto-satisfação do treinando, constituindo-se um agente motivador comprovado. Abrange uma somatória de atividades que vão desde a aquisição de habilidade motriz até $O$ desenvolvimento de um conhecimento técnico complexo, incluindo também a assimilação de novas atitudes, bem como modificações de comportamentos em função de problemas sociais amplos.

Uma pesquisa realizada pelo Instituto de Administração da Universidade de São Paulo para o Conselho Federal de Mãode-obra do Ministério do Trabalho, no período de 1988/89, constatou que muitas organizações realizam treinamento enfocando-o como um momento de transmissão de idéias, conceitos e habilidades. $\mathrm{O}$ ideal seria conduzir o treinamento como um processo de formação e aperfeiçoamento profissional (Ferreira, 1993).

Davis e Newstrom (1992) consideram que o treinamento deve ser um processo contínuo, que prepare o indivíduo em sua totalidade, uma vez que as mudanças sociais são constantes e o homem é o agente responsável pela implementação destas mudanças na sociedade. Tal afirmação é ampliada por Salas e Cannon-Bowers (2001) ao esclarecerem que as organizações tiveram que mudar a visão de treinamento como algo separado e sozinho, para um evento completamente integrado com as estratégias da organização.

Para Gil (1994) o treinamento nas organizações tem sido desenvolvido com diferentes enfoques. Nas primeiras décadas do século XX, assumiu a forma de adestramento, visando os aspectos físicos do trabalho - período coincidente com a hegemonia da Escola Clássica de Administração. O homem não era tido como um ser identificado com a organização, mas que essencialmente trabalhava em função do dinheiro.

Com o aparecimento da Escola das Relações Humanas, o treinamento passou a abranger aspectos psicossociais do indivíduo, visando a capacitação dos trabalhadores para o desempenho das tarefas, mas também com objetivos voltados para o relacionamento interpessoal e sua integração organizacional.

$\mathrm{Na}$ época atual, considerada como a era da informação, em que a tecnologia aliada à globalização econômica decreta novas formas de progresso e comunicação, as empresas não têm outra alternativa a não ser empenharem-se nesta empreitada da modernidade. Então, as organizações, utilizando-se do treinamento, programam-se com a finalidade de manter seus funcionários a par das novas técnicas e conceitos que se alteram constantemente (Bricchi,1998; Pastore, 1996).

A literatura demonstra que houve um aumento no investimento em treinamentos. Recentemente, estimativas sugerem que nos Estados Unidos os valores despendidos giram em torno de 55,3 bilhões a 200 bilhões de dólares anualmente (Bassi \& Van Buren 1999; Martocchio, 1998). Salas e Cannon-Bowers (2001) acreditam que isto ocorra pautado na crença de que os investimentos feitos em treinamento podem ser justificados em termos de melhorias organizacionais, aumento da produtividade, lucro, segurança, redução de erros e aumento na participação de mercado.

Em contrapartida, Rocha (1998) coloca que raramente percebe-se a aplicação efetiva do conteúdo transmitido num treinamento. Vale lembrar que um estudo de Georgenson (1982) estimava que somente $10 \%$ do que era gasto com treinamento resultava na transferência dos conhecimentos adquiridos para a situação de trabalho. Desde então, outros estudos têm se preocupado em identificar quais são as variáveis contributivas para a eficácia do treinamento.

Ferreira (1993), por exemplo, efetuou um trabalho objetivando avaliar os benefícios de um programa de treinamento na área gerencial com 157 indivíduos, os quais ocupavam cargos gerenciais de uma empresa sediada na capital e com unidades administrativas e operacionais no interior do Estado de São Paulo.

Os resultados da pesquisa mostraram que, concomitantemente ao aperfeiçoamento dos conhecimentos, 
habilidades e atitudes por parte dos sujeitos, estes também tomaram consciência de seu papel na organização, que por sua vez, requer uma postura profissional, consciente e responsável. Entre os benefícios gerados para com a organização está o melhor desempenho do gerente e de sua equipe, o que também desencadeou motivação, satisfação e aproveitamento dos recursos humanos à disposição deste colaborador. Tais eventos refletiram em maior produtividade, agilidade no atendimento aos clientes e melhor qualidade dos serviços prestados.

Considerando a conseqüência do treinamento tanto para as pessoas quanto para as organizações, Bricchi (1998) alerta para alguns obstáculos que precisam ser ultrapassados a fim de que o treinamento promova sucesso e satisfação a ambas as partes engajadas na sua execução. Um deles concerne à resistência individual à mudança já que, por vezes, os programas fixam-se nos aspectos técnicos, deixando questões atitudinais à margem. Por exemplo, uma modificação na forma de operar uma máquina pressupõe mudanças no manuseio, comportamento e maneira de pensar, o que não acontece, caso o colaborador não seja conscientizado do motivo de tal circunstância.

Para Bricchi (1998), as pessoas sofrem com o desconforto ou insegurança gerados por fatores relacionados indiretamente com o treinamento. Deste modo, para que o treinamento dê resultados não se pode abster da vontade do ser humano de apreender, reciclar-se e mudar. Diante disto, a autora enfatiza a importância de atentar-se para pontos como as percepções do funcionário e da empresa quanto ao que precisa ser melhorado que devem ser compatíveis; o funcionário deve ter potencial e estar motivado para aprender, além de ter suas ansiedades e medos detectados; os princípios e valores implícitos no conteúdo devem ser praticados pelos superiores; o objetivo final a ser atingido deve estar bem definido.

Com base na preocupação de manter seus funcionários atualizados, adota-se uma visão sistêmica do treinamento, mais preocupada com o contexto organizacional. Assim, o treinamento se transforma num meio de suprir as carências dos indivíduos em termos de conhecimentos, habilidades e atitudes, para que possam desempenhar as tarefas necessárias ao alcance dos objetivos do indivíduo e da organização. (Gil, 1994; Salas \& Cannon-Bowers, 2001).

Decorrente do paradigma de modelo sistêmico conta-se atualmente com mais teorias, modelos, resultados empíricos, revisões e meta-análises que contribuem para a realização de novos tipos de treinamento que incluem ações de aprendizagem, treinamento just-in-time, mentoring, coaching, aprendizagem organizacional e outros que são comumente explorados (Salas \& Cannon-Bowers, 2001).

$\mathrm{Na}$ revisão da literatura sobre treinamento, Salas e Cannon-Bowers (2001) delineiam as etapas necessárias para a realização de um treinamento eficaz e os principais achados referem-se a:
- Condições antecedentes ao treinamento (características individuais, motivação para treinamento, pré-condições ambientais);

- Métodos de treinamento e estratégias instrucionais (Ex.: aprendizagem específica, tecnologia de ensino e treinamento a distância, jogos e treinos baseados em simulação, equipes de treinamento); e

- Condições pós-treinamento (avaliação do treinamento e transferência de treinamento- manutenção e generalização do comportamento).

Diante disto, compreende-se que diversos fatores devem ser considerados quando a questão do treinamento está em foco. Atenção especial parece ser dada às reais necessidades de treinamento, uma vez que são de suma importância para o êxito dos seus resultados, ao mesmo tempo em que ainda carecem de uma metodologia mais efetiva.

Segundo Salas e Cannon-Bowers (2001), uma possível estratégia envolveria a análise organizacional e da tarefa, respondendo onde o treinamento é necessário, quais necessidades precisam ser atingidas e quem o necessita, todavia, esta é uma possibilidade que precisa ser melhor estudada.

Sob o ponto de vista de Rocha (1998), a identificação correta das necessidades de treinamento e desenvolvimento é crucial para que os objetivos sejam alcançados com êxito. Muitos executivos utilizam esta ação como estratégia de motivação e, no entanto, sabe-se que influenciam no desempenho pessoal outros aspectos tais como a falta de feedback e, às vezes, a vontade do próprio colaborador. Em outros casos, o treinamento é empregado como fator punitivo ao funcionário, à medida que este está apresentando baixos índices de produtividade e a empresa, por algum motivo, não quer ou não pode demiti-lo. Em contrapartida, o treinamento, muitas vezes, é considerado uma fuga ou até mesmo lazer pelos empregados, comprometendo sua assimilação, tanto pela desatenção como pela falta de comprometimento.

$\mathrm{O}$ autor notifica ainda haver expectativas tanto da empresa quanto do colaborador, que originam dúvidas e anseios frente ao treinamento. Hoje, as organizações usufruem de diversas técnicas com o intuito de fixar o que está sendo ensinado aos participantes do treinamento. Pressupondo que as pessoas têm características diferentes e assim, distintas capacidades de abstração, é preciso salientar que a escolha da metodologia de ensino passa, necessariamente, pelo conhecimento prévio do perfil de cada participante. Ou, do contrário, corre-se o risco da frustração de todos os envolvidos.

A pesquisa de Tannenbaum, Cannon-Bowers e Mathieu (1993) revelou que as atividades que ocorrem antes do treinamento fornecem um impacto sobre quão efetivo o treino poderá vir a ser, além disso, é válido orientar-se por ao menos três norteadores: 1) o que os treinandos trazem para o treinamento; 2) variáveis que engajam o aluno a participar das atividades; e 3) como o 
treinamento pode ser preparado para maximizar a experiência de aprendizado.

Colquitt, LePine e Noe (2000) realizaram um estudo metaanalítico sobre motivação para treinamento e sumarizaram a literatura de 20 anos sobre o tema, seus antecedentes e sua relação com os resultados de treinamento, incluindo conhecimentos, aquisição de habilidades e transferência. Os dados demonstram que os preditores da motivação para o treinamento e seus possíveis resultados incluem aspectos individuais como locus de controle, consciência, ansiedade, idade, habilidade cognitiva, auto-eficácia, envolvimento no trabalho e aspectos situacionais como clima organizacional. Esses dados trazem o desafio do desenvolvimento de recursos instrucionais que considerem tais pontos para o desenvolvimento de um ambiente de aprendizagem que seja cada vez mais propício aos treinandos. Os autores apontam também que a fase de análise de necessidades de treinamento (individuais e organizacionais) oferece informações importantes que podem influenciar na motivação para $o$ treinamento e na aprendizagem, além disso, o uso de técnicas que aumentam a eficácia do treinando e enfatizam os benefícios do treinamento para o trabalho e para a carreira exercem influência na auto-eficácia e no envolvimento do indivíduo.

As estratégias instrucionais vêm recebendo maior atenção dos estudiosos e são definidas como o conjunto de ferramentas (Ex.: análise de tarefas), métodos (Ex.: simulação) e conteúdo (Ex.: competências requeridas) que, quando combinadas, criam um modelo instrucional (Salas \& CannonBowers, 2001). As estratégias mais efetivas (ainda que não exista um modelo único de aprendizagem) parecem basearse em quatro princípios básicos: 1) apresentam informações e/ou conceitos relevantes para a aprendizagem; 2) apresentam os conhecimentos e habilidades que devem ser aprendidos; 3) criam oportunidade para os treinandos praticarem tais habilidades; e 4) provêem feedback para o treinando durante e depois de suas práticas.

Vale lembrar que, especialmente com o auxilio da tecnologia, os recursos instrucionais estão muito mais avançados, contando com ferramentas como vídeo conferências, cursos on-line, internet, educação à distância, simulações e ambientes virtuais, jogos baseados em computadores e outros que visam a otimizar a aprendizagem e sua retenção.

Outro ponto analisado diz respeito ao papel do treinador, neste caso, Towler e Dipboye (2001) realizaram uma pesquisa com 135 universitários e descobriram que a expressividade e a organização textual e de discurso do treinador facilitam a recordação do conteúdo e a conseqüente resolução de problemas por parte dos treinandos.

Finalizando as etapas do treinamento, encontra-se a função de avaliação e, neste sentido, Smith-Jentsch, Salas e Brannick
(2001) esclarecem que, além do suporte do líder, o delineamento do treinamento, as características do treinando, o contexto organizacional e o clima da equipe são importantes preditores no impacto dos resultados do treinamento (aprendizagem e retenção) e nas condições de transferência (generalização e manutenção).

$\mathrm{Na}$ visão de Rabelo, Bresciani Filho e Oliveira (1995) a avaliação do treinamento éuma fase bastante importante, podendo oferecer diversos benefícios como: auxílio na adequação do treinamento com o plano estratégico da empresa; apoio no rastreamento daqueles que foram treinados e dos que necessitam de treinamento; identificação das barreiras que confrontam as equipes e dificultam seu progresso; estabelecimento de critérios para reconhecimento e recompensa dos participantes; e geração de oportunidades para uma retroalimentação, objetivando a melhoria contínua do programa.

Algumas pesquisas têm buscado delinear metodologias e/ ou instrumentos que tornem mais fidedigna a tarefa de avaliar os resultados de treinamento, como é o caso do estudo de Taylor, Lamers, Vincent e O’Driscoll (1998) que buscou verificar a eficácia dos questionários de auto-avaliação em comparação com medidas tidas como mais objetivas de treinamento (Ex.: simulação). Nesse estudo, os resultados demonstraram congruência entre as auto-avaliações e as medidas objetivas. Os autores acreditam que estes dados diferem de achados anteriores, justamente porque os estudos prévios não enfatizavam ao participante que a proposta de auto-avaliação era somente para avaliar o treinamento e não os indivíduos. Com esta ênfase os autores entendem que seja possível reduzir a tendência dos respondentes em superestimar as auto-avaliações.

Já Abbad, Borges-Andrade, Sallorenzo, Gama e Morandini (2001) investigaram o relacionamento de variáveis de suporte organizacional, suporte à transferência de treinamento e características dos treinandos com variáveis de reação, aprendizagem e impacto do treinamento no trabalho, em 2907 sujeitos de 226 cursos oferecidos por uma organização pública e verificaram que a aprendizagem não está diretamente relacionada com reação, nem com impacto. As características dos treinandos influenciam a aprendizagem e reação, além disso, a transferência de aprendizagem para o trabalho depende do contexto póstreinamento.

Outro exemplo é o trabalho de Borges-Andrade, Pereira, Puente-Palácios e Morandini (2002) que buscou verificar o impacto institucional de cursos organizados para melhorar os processos de gestão de empresas de pesquisa agropecuária, utilizando-se de um modelo de avaliação que toma por base a avaliação de treinandos, superiores e colegas para averiguar o impacto do curso tanto para o indivíduo, quanto para a organização. Os resultados demonstraram que é possível utilizar uma metodologia de avaliação de impacto, tomando por base o modelo de avaliação institucional. 
Num estudo direcionado por Rabelo e colaboradores (1995), explorou-se a maneira como a organização do treinamento afeta a implementação e o desempenho de programas de qualidade numa empresa, por meio de questionários e entrevistas abertas com vários níveis gerenciais de 19 empresas fabricantes de autopeças, metal-mecânicas, com produção seriada e em massa. A análise comparativa entre a pontuação conferida às empresas na área de qualidade com a pontuação conferida à organização do treinamento mostrou, entre outros resultados, que nenhuma empresa mal colocada nos critérios de treinamento obteve uma boa pontuação para sua gestão de qualidade; os gerentes entrevistados reconheceram a importância das políticas de treinamento para explicar os resultados (positivos ou negativos) apresentados na área de garantia da qualidade.

Nas conclusões de Rabelo e colaboradores (1995), obtêmse algumas notas interessantes, como o fato de haver um número significante de empresas que ainda não quantificam o montante investido em treinamento. Esta questão levou-os a indagar até que ponto as empresas consideram o treinamento uma atividade estratégica. Outro dado ressaltado é a ocorrência de mais ampliações no uso de treinamento gerencial e no treinamento dirigido ao pessoal semi e não-qualificado da produção.

No que diz respeito ao aumento do treinamento gerencial pode-se supor que isto é decorrente da importância deste cargo, bem como pelo fato de que a maior parte dos problemas relativos à qualidade é causada por sistemas controlados pela gerência, portanto, são eles que detêm o poder para resolvê-los. A pesquisa apontou que $25 \%$ das empresas, em posse da informação, dedicam mais de 10 dias/ano ao treinamento gerencial. Duas possíveis explicações encontradas, pelos autores acima citados, sobre a ampliação do treinamento dirigido ao pessoal semi e não-qualificado da produção foram a base de escolaridade ser inferior se comparada com a de países industrializados e a média de treinamento dedicada a este pessoal ser baixa.

Novelli (1998) esclarece que as organizações já estão conscientizando-se do esgotamento do modelo segmentado do trabalhador e reservando maior espaço para o mesmo conhecer as relações com outras funções da empresa. Nesse âmbito, o funcionário cerca-se de condições que garantem o exercício das tarefas com maior autonomia, criatividade, inovação e responsabilidade. O papel do treinamento transcende, deste modo, de mero instrumento de disseminação de ações a um parceiro na concepção estratégica. A avaliação (de eficiência e eficácia) de treinamento, ao invés de reduzir-se a checar desvios entre objetivos desejados e resultados observados, assume um papel flexível e abrangente o suficiente para captar tendências e sustentar a tomada de decisão do pessoal de linha e do staff de recursos humanos.

Pode-se associar a visão citada anteriormente, com o estudo de Cannon-Bowers e Salas (2001) sobre a importância do constructo de cognição compartilhada no desempenho de equipes. $\mathrm{O}$ conceito permite a compreensão do desempenho por meio do conhecimento de como os membros interagem uns com os outros e com a própria tarefa, ajudando a entender quais são os elementos para a eficácia do trabalho em equipe que podem levar a melhoria do desempenho.

Nesta mesma linha, Marks, Sabella, Burke e Zaccaro (2002) realizaram um estudo sobre o impacto do treinamento denominado cross-training, no qual o mesmo indivíduo é treinado em várias funções e o modelo de cognição compartilhada na eficiência de times de trabalho, demonstrando que o modelo pode trazer benefícios para o desempenho da equipe e da organização, ainda que algumas questões necessitem de maiores investigações futuras para serem respondidas, como por exemplo, o tipo de equipe que mais se beneficia com este modelo de trabalho.

O cross training faz lembrar a noção de empregado polivalente ou multifuncional assinalada por Albuquerque (1992) e referese ao funcionário que possui alto nível de qualificação, podendo executar vários tipos de tarefas sem ficar preso a um posto específico de trabalho. O mesmo autor notifica que tais condições são favorecidas pelo uso intensivo de treinamento no trabalho através do rodízio de funções.

Segundo Macian (1987), o grande dilema do processo de treinamento empresarial é que de um lado existe a necessidade de se especializar o funcionário, montando seu perfil em função dos moldes de conduta previstos pela empresa, o que de certa forma corresponde a um processo de instrumentalização do homem; de outro lado, existe o dever de não aprisionar a criatura humana a regras e padrões predeterminados, não só por um problema de consciência moral, como pelas conseqüências desastrosas que podem advir para a própria empresa, decorrentes da produção de um protótipo de robô, morto em termos de criatividade e imaginação, incapaz de propor novos processos ou de transpor fronteiras tradicionais na busca de novas propostas. Portanto, para essa autora, nunca deve ser ignorada a dimensão pessoal nos planos de treinamento, garantindo ao indivíduo sua condição de criatura humana, capaz de atuar conscientemente como um agente de mudança do cenário produtivo.

Para Carvalho e Nascimento (1997), o treinamento só se completa na medida em que a aquisição de conhecimentos e informações possibilita ao treinando mudança de comportamento (formas de conduta). Nesse sentido, a aprendizagem caracterizase como o processo de aquisição da capacidade de usar o conhecimento e ocorre em função da prática e experiência crítica, produzindo uma mudança relativamente permanente no comportamento.

As informações aqui reunidas buscam demonstrar o quão amplo e complexo pode ser o universo do treinamento, muitas variáveis estão imbricadas na situação e a atenção fornecida a cada uma delas ditará a probabilidade de êxito ou fracasso da ação. Certamente esta não é uma tarefa fácil e 
o profissional responsável pelo treinamento não poderá ser o único responsável pelos resultados positivos ou negativos que venham a ser atingidos, pois treinar pessoas exige a composição de um cenário formado por treinandos, treinadores, organização, objetivos, tempo e recursos disponíveis, dentre outros, contando ainda com a variação do grau de comprometimento dos envolvidos.

Com base nisso, a principal meta deste estudo foi identificar como as organizações públicas e privadas do Estado de São Paulo estão administrando e desenvolvendo suas políticas de treinamento e desenvolvimento e comparar essas organizações em termos de empresas nacionais e multinacionais, tamanho da empresa (com mais ou menos de 500 funcionários) e em função de possuir ou não Departamento de Recursos Humanos.

\section{Método}

\section{Participantes}

Foram estudadas nesta pesquisa 300 empresas do Estado de São Paulo, com no mínimo 100 funcionários. Solicitou-se que as empresas fossem representadas no estudo pelo responsável do setor de Recursos Humanos, o qual estaria incumbido de responder ao instrumento.

\section{Material}

Neste relato estão sendo consideradas as questões da escala "Treinamento e Desenvolvimento" de um questionário de 10 escalas, especialmente formulado com base no instrumento utilizado por Brewster e Hegewich (1994), adaptado e pré-testado pelos autores do presente projeto. Esta parte era composta por 11 questões fechadas, mais especificamente versando sobre as seguintes dimensões:

1) Proporção do gasto anual em salários e em treinamentos;

2) Quantidade de dias por ano despendidos com treinamento;

3) Crescimento do investimento financeiro direcionado ao treinamento nos últimos 3 anos;

4) Análise das necessidades de treinamento;

5) Métodos utilizados para a análise das necessidades de treinamento;

6) Controle da eficiência de treinamento e métodos utilizados para tal;

7) Procedimentos utilizados direcionados ao treinamento de pessoal; e

8) Áreas que constituirão a principal necessidade de treinamento nos próximos 3 anos.

O instrumento foi traduzido do inglês para o português, sendo executada posteriormente sua reversão para o idioma original a fim de garantir sua adequação.

\section{Procedimento}

Inicialmente foi elaborado por meio de um banco de dados o rol de empresas possíveis para composição da amostra, tendo como critério as empresas nacionais ou multinacionais, públicas ou privadas, localizadas no estado de São Paulo, que independente do setor produtivo contassem com no mínimo 100 funcionários, o que totalizou 3500 empresas.

Uma vez definidas as empresas participantes, o instrumento foi enviado por correio direcionado ao setor de recursos humanos, juntamente com uma carta explicativa na qual constava a necessidade do instrumento ser preenchido pelo responsável do setor de Recursos Humanos (R.H.) ou pelo diretor da empresa caso não houvesse um departamento de R.H. Anexo ao instrumento havia um envelope auto-endereçado e selado. $\mathrm{O}$ prazo para o retorno do instrumento foi de até 60 dias.

Ao final desse período foram enviados novos instrumentos às empresas que não retornaram os mesmos, acompanhados de outra carta explicativa do estudo, sendo desta vez o tempo de resposta de 45 dias. Em função do baixo índice de devolução, foram identificados os responsáveis pela área de Recursos Humanos das organizações, com os quais foram feitos contatos telefônicos de forma a otimizar a participação. Após esse procedimento, obteve-se um total de 300 respondentes que tiveram garantia sobre o sigilo das informações fornecidas.

Em relação à análise, os dados foram computados de três formas diferentes, de acordo com o tipo de questão:

a) única escolha - na qual o respondente só poderia assinalar uma única alternativa, o que possibilitou a totalização de 100\% por questão;

b) múltipla escolha excludente - na qual o respondente deveria realizar uma única escolha em cada item da questão, o que possibilitou a totalização de $100 \%$ por item;

c) múltipla escolha não excludente - na qual o respondente poderia assinalar tantas alternativas quantas fossem necessárias, o que levou a uma totalização maior que $100 \%$ por questão.

Além disso, para a realização do teste do qui-quadrado adotouse um procedimento do Statistical Packeage for Social Sciences (SPSS) que calcula as probabilidades exatas pelo método de Monte Carlo que simula 10000 amostras supondo que a hipótese nula é verdadeira (independência entre as variáveis), a partir das freqüências marginais observadas, e verifica qual a probabilidade de ocorrência da distribuição específica que é testada. Este procedimento resulta em probabilidades não viesadas (para mais informações ver SPSS, 1993).

Essa prova foi utilizada para comparar as organizações em termos de empresas nacionais e multinacionais, tamanho da empresa (com mais ou menos de 500 funcionários) e em função de possuir ou não Departamento de Recursos Humanos, sendo que as tabelas completas só foram colocadas quando as três variáveis mostraram-se significativas, caso contrário, apenas os resultados descritivos foram discutidos.

\section{Resultados}

Determinar a proporção do gasto anual dividido entre salários e treinamento foi a primeira questão levada aos 
participantes e obteve-se que $44,67 \%$ dos respondentes não souberam discriminar tal evento. Estes resultados permitem uma alusão ao estudo realizado por Rabelo e colaboradores (1995), em que os autores também ressaltam que um considerável número de empresas não quantifica o montante gasto em treinamento, o que levaria a indagar até que ponto essas empresas o consideram uma atividade estratégica, pois, se como aponta Chiavenato (1996), o investimento gradativo no aperfeiçoamento e treinamento de pessoal é o principal desafio de RH. Essa preocupação parece ser apenas de um seleto grupo de organizações, já que o que se apresenta neste trabalho é uma preocupação com o treinar sem maior sistematização ou controle de tal atividade.

Quando indagados a respeito do tempo de treinamento por ano destinado a certos cargos, em termos gerais, as porcentagens encontradas a partir das respostas confirmam a discussão da questão anterior, pois a maioria dos participantes não tem conhecimento da média de dias por ano que os colaboradores recebem de treinamento. Descrevendo mais detalhadamente os resultados, teve-se para a casela Não sei, referindo-se a cada cargo a seguir exposto, os seguintes números de assinalações: Gerente (30,33\%), Técnico (30,67\%), Auxiliarde Escritório (32,33\%) e Operário (31\%). Revelando talvez, as dificuldades enfrentadas por algumas empresas em acompanhar os constantes avanços mercadológicos, implicando em rever seus procedimentos e planejamento ou, até mesmo, pode-se pensar que o problema esteja relacionado com a defasagem na comunicação entre os setores, de maneira a influenciar e dificultar a discriminação deste tempo voltado ao treinamento.

Em contrapartida, nas empresas que apontaram um número de dias direcionado ao treinamento, observou-se que todos os cargos abordados na questão receberam uma margem similar de dias de treinamento. A afirmativa não corrobora com o destacado por Rabelo e colaboradores (1995) que revelaram haver mais ampliação no uso de treinamento gerencial e no dirigido ao pessoal semi e não-qualificado da produção. Tal diferença pode ser pensada com relação aos novos desafios que vêm sendo enfrentados pelas organizações e que forçam a empresa a melhorar o nível de qualificação de todos os trabalhadores. Outra possível explicação pode ser que a pouca atenção atribuída ao treino de algumas categorias profissionais esteja sendo mais claramente sentida pelas empresas que buscam ajustar-se às novas demandas que enfatizam, por exemplo, a necessidade do trabalho em equipe, a criatividade, a pró-atividade e outros como forma de enfrentar a competitividade.

É sempre importante destacar que a tomada de iniciativa depende, entre outros fatores, da filosofia empresarial que se mostra na maioria das vezes estável e duradoura, o que acarreta conflitos elentidão na fixação de metas. A prerrogativa é defendida por Carvalho e Nascimento (1997), mas tem possibilidade de relação com os dados explanados na referida questão, a qual é possível acompanhar mais detalhadamente na Tabela 1, pois qualquer ajustamento pretendido em termos de aumento de dias voltados a treinamento deve estar de acordo com objetivos e decisões das outras áreas e classes hierárquicas da empresa, que nem sempre são flexíveis.

No que se refere ao crescimento ou não de investimento financeiro direcionado ao treinamento, grande parte dos participantes apontou que no período compreendido entre os últimos 3 anos houve aumento para os cargos: Operário, Técnico e Gerente. Talvez tais funções requeiram recursos utilizados no treinamento que despendam maiores gastos, portanto, quantificam um investimento maior. Vale salientar que estes dados vão ao encontro das observações de Bassi e Van Buren (1999) e

Tabela 1

Descrição dos Dias Gastos em Treinamento de acordo com Função

\begin{tabular}{lrrrrrrrr}
\hline Itens & \multicolumn{2}{c}{ Gerente } & \multicolumn{2}{c}{ Técnico } & \multicolumn{2}{c}{ Auxiliar } & \multicolumn{2}{c}{ Operário } \\
& $\mathrm{F}$ & $\mathrm{F} \%$ & $\mathrm{~F}$ & $\mathrm{~F} \%$ & $\mathrm{~F}$ & $\mathrm{~F} \%$ & $\mathrm{~F}$ & $\mathrm{~F} \%$ \\
\hline $1-5$ & 71 & 23,67 & 69 & 23,00 & 85 & 28,33 & 78 & 26,00 \\
$6-10$ & 39 & 13,00 & 41 & 13,67 & 30 & 10,00 & 36 & 12,00 \\
$11-15$ & 18 & 6,00 & 14 & 4,67 & 5 & 1,67 & 11 & 3,67 \\
$16-20$ & 9 & 3,00 & 11 & 3,67 & 10 & 3,33 & 14 & 4,67 \\
$21-30$ & 9 & 3,00 & 6 & 2,00 & 1 & 0,33 & 7 & 2,33 \\
$31-40$ & 3 & 1,00 & 6 & 2,00 & 2 & 0,66 & 2 & 0,67 \\
Acima de & 0 & 0 & 0 & 0 & 0 & 0 & 2 & 0,66 \\
Não Sei & 91 & 30,33 & 92 & 30,67 & 97 & 32,33 & 93 & 31,00 \\
Não Tem & 7 & 2,33 & 6 & 2,00 & 10 & 3,33 & 3 & 1,00 \\
Variável & 1 & 0,33 & 1 & 0,33 & 1 & 0,33 & 3 & 1,00 \\
Não & 52 & 17,33 & 54 & 18,00 & 59 & 19,67 & 51 & 17,00 \\
responderam & & & & & & & & 100,00 \\
Total & 300 & 100,00 & 300 & 100,00 & 300 & 100,00 & 300 & 100,00 \\
\hline
\end{tabular}


Martocchio, (1998) quanto ao aumento dos investimentos em treinamento. Isso demonstra uma aproximação da realidade brasileira com as pesquisas internacionais, podendo-se pensar também que exista na realidade do Estado de São Paulo uma maior conscientização quanto à importância do uso do treinamento.

Oestudo estatístico por meio da prova qui-quadrado apontou significância da variável Multinacional nesta questão para as categorias Gerente $\left(\chi^{2}=11,28 ; g l=3 ; p=0,05\right)$ e Auxiliar de escritório $\left(\chi^{2}=8,44 ; g=3 ; p=0,05\right)$, enquanto Possuir $R H$ denotou ser significativa para os itens Témnico $\left(\chi^{2}=13,54 ; g=3 ; p=0,05\right)$ e Operário $\left(\chi^{2}=10,50 ; g l=3 ; p=0,05\right)$.

A variável Multinacional sendo significativa para os descritores Gerente e Auxiliar de escritório pode indicar a atenção voltada a tais cargos pelo referido grupo de organizações, já que as categorias de profissionais em questão exercem funções essencialmente administrativas que, por sua importância, originam grande preocupação, especialmente nos dias atuais. Os gerentes, por exemplo, controlam sistemas de qualidade e detêm poder para resolver problemas na área. Algumas empresas apostam na melhoria da qualidade dos serviços prestados, na maior agilidade no atendimento aos clientes e na maior produtividade ao disporem investimentos em treinamento gerencial, pois confiam nos benefícios trazidos por tal (melhor desempenho, motivação, satisfação e aproveitamento dos recursos humanos à disposição etc), o que pôde ser observado no estudo de Ferreira (1993).

O fato da variável Possuir $\mathrm{RH}$ ter mostrado significância para os itens técnico e operário faz refletir a respeito da necessidade de um planejamento que tenha por objetivo desenvolver habilidades e funções de tais cargos, sendo este um trabalho específico de RH, justificando assim a demanda por sua existência.

Uma prática importante ao se falar em treinamento diz respeito à análise sistemática das suas necessidades, uma vez que esta é fundamental para o sucesso dos resultados. Entretanto, a análise de necessidades ainda não possui uma descrição metodológica clara e eficaz (Rocha, 1998; Salas \& Cannon-Bowers, 2001).

Os resultados da presente pesquisa apontam que os participantes em sua maioria realizam a análise de necessidades
(70,33\%), mas resta saber se esta análise ocorre de forma aprofundada e não superficial, uma vez que, quando bem feita, possibilita uma rica discussão sobre se de fato estas necessidades existem e devem ser supridas com treinamento ou se estão aparecendo apenas como subterfúgio de outros problemas organizacionais existentes, situação esta em que o treinamento se torna dispensável na maioria das vezes. Sendo a variável Multinacional significativa neste caso - $90 \%$ das multinacionais disseram sim para análise das necessidades e a mesma resposta foi dada por $66,9 \%$ das não-multinacionais - é possível supor que pelo contato maior com a política internacional de estratégia empresarial, as multinacionais tenham aderido à prática da análise com maior rapidez.

Outro item analisado que se mostrou significante quando comparado com a existência da análise das necessidades de treinamento foi o fator Possuir $\mathrm{RH}$, uma vez que $75,7 \%$ das empresas que têm um $\mathrm{RH}$ em sua estrutura realizam a análise das necessidades, enquanto somente $48 \%$ das que não possuem esta área o fazem. Ao que parece esta é uma preocupação mais específica de empresas que possuem o departamento de recursos humanos, as quais demonstram uma atenção maior às necessidades de treinamento e talvez os implemente com maior sucesso por contar com profissionais especializados para isto.

Na Tabela 2 estão citados alguns dos métodos mais usados pelas empresas que analisam as necessidades de treinamento. Os dados da Tabela 2 estão baseados em uma questão de múltipla escolha. Desta forma, verificou-se que a maioria dos respondentes utiliza-se Sempre dos diversos métodos para analisar a necessidade de treinamento, tendose: Avaliação de treinamento (35,67\%), Necessidades dos funcionários (35,33\%), Necessidades de linha de gerenciamento (25,67\%), Estimativa de desempenho (21,33\%) e Análise do planejamento de negócios e serviços (20\%). Em seguida, como métodos utilizados Quase sempre surgiram tais freqüências: Estimativa de desempenho (15\%), Necessidades dos funcionários (15\%), Necessidades de linha de gerenciamento (14,33\%), Análise do planejamento de negócios e serviços (13,33\%) e Avaliaşão de treinamento (11,67\%). Vale ressaltar

Tabela 2

Métodos Usados para Análise das Necessidades de Treinamento

\begin{tabular}{|c|c|c|c|c|c|c|c|c|c|c|}
\hline \multirow[t]{2}{*}{ Itens } & \multicolumn{2}{|c|}{$\begin{array}{l}\text { Análise do planejamento } \\
\text { de negócios e serviços }\end{array}$} & \multicolumn{2}{|c|}{$\begin{array}{l}\text { Avaliação de } \\
\text { treinamento }\end{array}$} & \multicolumn{2}{|c|}{$\begin{array}{l}\text { Necessidades delinha } \\
\text { de gerenciamento }\end{array}$} & \multicolumn{2}{|c|}{$\begin{array}{l}\text { Estimativa de } \\
\text { desempenho }\end{array}$} & \multicolumn{2}{|c|}{$\begin{array}{l}\text { Necessidades } \\
\text { dos funcionários }\end{array}$} \\
\hline & $\mathrm{F}$ & $\mathrm{F} \%$ & $\mathrm{~F}$ & $\mathrm{~F} \%$ & $\mathrm{~F}$ & $\mathrm{~F} \%$ & $\mathrm{~F}$ & $\mathrm{~F} \%$ & $\mathrm{~F}$ & $\mathrm{~F} \%$ \\
\hline Sempre & 60 & 20,00 & 107 & 35,67 & 77 & 25,67 & 64 & 21,33 & 106 & 35,33 \\
\hline Quase sempre & 40 & 13,33 & 35 & 11,67 & 43 & 14,33 & 45 & 15,00 & 45 & 15,00 \\
\hline Algumas vezes & 38 & 12,67 & 30 & 10,00 & 29 & 9,67 & 43 & 14,33 & 35 & 11,67 \\
\hline Nunca & 14 & 4,67 & 4 & 1,33 & 9 & 3,00 & 6 & 2,00 & 1 & 0,33 \\
\hline Não responderam & 148 & 49,33 & 124 & 41,33 & 142 & 47,33 & 142 & 47,33 & 113 & 37,67 \\
\hline Total & 300 & 100,00 & 300 & 100,00 & 300 & 100,00 & 300 & 100,00 & 300 & 100,00 \\
\hline
\end{tabular}


que o número de Não-respondentes foi relativamente alto em todos os descritores e denota talvez a dificuldade em identificar as necessidades de treinamento.

Em relação à análise estatística feita pelo qui-quadrado, verificou-se que para a questão em pauta, que Possuir $\mathrm{RH}$ é significativo para o descritor Necessidades de linha de gerenciamento $\left(\chi^{2}=10,69 ; g=3 ; p=0,05\right)$. Foi verificado um escore de $50 \%$ de empresas que possuem RH e sempre usam esse método. Multinacional tem significância para Análise do planejamento de negócios e servicos e convergindo aos dados mais detalhados, constatou-se que $57,1 \%$ das multinacionais sempre usam o referido método, ao passo que também o fazem apenas $26 \%$ das não-multinacionais $\left(\chi^{2}=19,10 ; g l=3 ; p=0,05\right)$.

Muitas vezes, os métodos adotados não conferem fidedignidade com o propósito, prejudicando o desenvolvimento do pessoal e ocasionando gastos à empresa, a qual passa a não destinar mais verba ao treinamento. Se empregados corretamente, tais métodos poderiam ser usados como estratégia de motivação e contrapor outros aspectos que influenciam no desempenho pessoal, como falta de feedback e até mesmo de vontade do próprio colaborador (Rocha, 1998).

Em relação à Análise do planejamento de negócios e serviços realizarse com maior rigor pelas multinacionais faz supor que por serem diretamente influenciadas pelas políticas administrativas e econômicas externas, tendem a se voltar a técnicas que as descrevem com perfeição- atender a demanda, atribuindo maior qualidade ao produto. Já Necessidades de linha de gerenciamento é um método adotado por considerável parte das organizações que detêm um setor de RH. Então, a formação e o aprimoramento são considerados a partir das necessidades corporativas, setoriais e individuais identificadas.

Ao questionar a amostra sobre o fato de haver o controle da eficiência do treinamento, nota-se que $73,67 \%$ responderam $\mathrm{Sim}$ contra 18,67\% que afirmaram Não. Então, a eficiência do treinamento parece ser um aspecto controlado pela grande massa dos participantes, a qual utiliza variados modos para tal. Obtevese, através da análise estatística, que pertencer ao grupo das multinacionais, ter um número maior de funcionários e possuir RH são variáveis que denotam significância nesse contexto e provavelmente em virtude de contar com tais características, as empresas em questão estejam um passo à frente das demais. Entre as organizações que possuem Acima de 500 colaboradores em seu quadro, $84,7 \%$ Controlam a eficiência do treinamento $\left(\chi^{2}=6,03\right.$; $g l=2 ; p=0,05)$. Já nas Multinacionais, 91,1\% Realizam este controle $\left(\chi^{2}=12,48 ; g=2 ; p=0,05\right)$ e das que Possuem $R H, 79,6 \%\left(\chi^{2}=7,55\right.$; $g=2 ; p=0,05)$ o Fazem. Contudo, é preciso retomar a fala de Novelli (1998), a qual esclarece que a avaliação de eficiência do treinamento deveria assumir um papel flexível para captar tendências e sustentar a tomada de decisão do pessoal de linha e do staff de recursos humanos, ao invés de reduzir-se a checar desvios entre os objetivos almejados e os resultados observados.
Esse alerta carece de maior atenção das empresas em geral, pois os dados apontam que prevalece o enfoque em ações que se mostram corriqueiras no cenário organizacional, como Feedback informal da linha de gerenciamento (50,33\%) e Avaliação formal imediatamente após o treinamento $(48,33 \%)$.

Outro ponto investigado concerne às perspectivas mais aplicadas na organização. Aqui, convém pontuar a porcentagem dos itens mais assinalados, sendo eles Avaliação de desempenho_com 51,33\% citações, seguido por Planos de sucessão com 18,67\% e 18\% para Entrevistas anuais sobre o desenvolvimento da carreira.

De acordo com os dados obtidos sobre as empresas que utilizam a Avaliação de desempenho, verificou-se que a variável mais relevante encontrada foi Possuir $R H$, já que 65,8\% das respostas concedidas por estas organizações foram afirmativas para o item $\left(\chi^{2}=8,56 ; g l=1 ; p=0,05\right)$. Tal fato pode ser justificado uma vez que o departamento de RH possui maior conhecimento dos métodos formais para mensuração e avaliação do desenvolvimento profissional de um funcionário.

Por meio da prova estatística do qui-quadrado verificou-se que as três variáveis usadas na análise dos dados (Ser ou não multinacional, Possuir ou não RH e Número de funcionários) foram significativas em relação à utilização de Entrevistas anuais sobre o desenvohimento da carreira e ao uso de Planos de sucessão.

Das empresas com menos de 500 funcionários, 79,7\% não usam regularmente Entrevistas anuais sobre o desenvolvimento da carreira $\left(\chi^{2}=6,08 ; g=1 ; p=0,05\right)$, assim como $82,6 \%$ das não-multinacionais $\left(\chi^{2}=16,47 ; g=1 ; \mathrm{n} . p=0,05\right)$ e $94,7 \%$ das que não têm departamento $\operatorname{de} \operatorname{RH}\left(\chi^{2}=4,66 ; g l=1 ; p=0,05\right)$.

Referindo-se à adoção de Planos de sucessão, praticamente não há proposta de serem feitos em empresas com menos de 500 funcionários, como apontam 89,9\% das respostas $\chi^{2}=17,48$; $g l=1 ; p=0,05)$. Com relação à variável Multinacional, $79,2 \%$ das empresas nacionais também não o fazem $\left(\chi^{2}=8,25 ; g=1 ; p=0,05\right)$ e nas empresas que não possuem $\mathrm{RH}, 100 \%$ apontaram não utilizarem Planos de sucessão $\left(\chi^{2}=7,81 ; g l=1 ; p=0,05\right)$.

Os resultados explanados permitem fazer alusão a um ponto muito debatido no mercado de trabalho das nações mais avançadas: a capacidade de flexibilização, que permite o ajuste às constantes inovações trazidas pela globalização e tecnologia (Pastore, 1996). No entanto, estes dados parecem se contrapor ao que se vê no cenário mundial, indicando talvez um atraso dessas empresas em relação ao mesmo.

Carvalho e Nascimento (1997) também pontuam a necessidade dos planos de formação profissional serem dinâmicos e atualizados. A noção de empregado polivalente ou multifuncionalé assinalada ainda por Albuquerque (1992) e referese ao funcionário que possui alto nível de qualificação, podendo executar vários tipos de tarefas sem ficar preso a um posto específico de trabalho. O mesmo autor notifica que tamanhas condições favorecem o uso intensivo de treinamento no trabalho através do rodízio de funções. 
Em relação aos demais descritores abrangidos nesta questão de aspectos regularmente utilizados pelas organizações, podese sublinhar que a Rotacão de trabalho planejada parece não ser uma prática comum entre as empresas de médio porte e sem o setor de RH, mais uma vez reforçando a idéia da distância entre o que vige no mercado externo e o que se faz no Estado de São Paulo. Já 80,50\% das respostas consentidas foram de empresas que têm Menos de 500 funcionários e Não usam este gênero $\left(\chi^{2}=3,89\right.$; $g l=1 ; p=0,05)$ e $94,7 \%$ dos respondentes disseram Não possuir departamento de RH e também Não utilizam o referido aspecto regularmente $\left(\chi^{2}=3,89 ; g=1 ; p=0,05\right)$.

Quanto ao gênero Esquemas especiaisparagerenciar, os resultados, ao indicarem a influência da variável Possuir $\mathrm{RH}-94,7 \%$ das respostas foram dadas por organizações que $\mathrm{Não}$ possuem $\mathrm{RH}$ $\left(\chi^{2}=4,31 ; g l=1 ; p=0,05\right)$ e Não utilizam este procedimento - fazem refletir acerca das vantagens de um processo de desenvolvimento de pessoal, que inclusive é abordado por Carvalho e Nascimento (1997); assim, este proporcionaria, entre outros, a melhoria dos padrões profissionais dos colaboradores com a possibilidade de melhor aproveitamento de suas aptidões; contudo, sua ausência implicaria em repensar ações.

Já o descritor Esquemas de experiência internacional para gerentes parece ser utilizado em baixa escala por organizações nacionais $89,4 \%$ delas Não usufruem de tal procedimento $\left(\chi^{2}=26,31 ; g=1\right.$; $p=0,05)$ - e com menos de 500 funcionários- $87,20 \%$ delas afirmaram $N a \tilde{o}$ adotar esse aspecto $\left(\chi^{2}=12,7 ; g l=1 ; p=0,05\right)$. $\mathrm{O}$ que de certa forma não surpreende, mas mostra a necessidade de maiores investimentos nas pessoas por parte das organizações, já que, concordando com Chiavenato (1996), o ser humano é o alavancador dos resultados dentro de uma empresa e apostar em seu desenvolvimento garante retornos à própria empresa.

As áreas que irão constituir a principal necessidade de treinamento nos próximos 3 anos, segundo as empresas respondentes, estão descritas na Tabela 3 .
Verificando os dados da Tabela 3, observa-se que estes estão descritos em função do número de respostas para cada item da questão e não do número total de sujeitos da amostra. Dessa forma, ao tratar das possíveis áreas que deterão necessidades de treinamento nos próximos 3 anos, tem-se: Administração de negócios e estratégia que aparece com $12,22 \%$ das considerações, acompanhada por Gerenciamento depessoal e supervisão com 11,78\% e Computadores e novas tecnologias com $11,59 \%$. Na seqüência, a categoria Qualidade recebeu $11,53 \%$ das respostas, Habilidades de atendimento ao cliente registrou $10,71 \%$ e Saúde e seguranca e ambiente organizacional somou $10,52 \%$. Quanto às demais áreas, vale destacar que as percentagens acumuladas resultam em valores abaixo de $10 \%$ para cada uma.

As empresas parecem estar se preocupando com as tendências previstas para um futuro próximo, em que se destacam as funções ligadas à gestão estratégica, à informática e à qualidade. Bricchi (1998) pontua que algumas vezes os programas de treinamento voltam-se aos aspectos técnicos, colocando questões atitudinais à deriva. É esperado que tal realidade sofra alterações e que a visão futurista dos sujeitos seja um exemplo do que há por vir em termos de humanização do trabalho.

\section{Conclusão}

É preciso esclarecer que apesar das organizações terem indicado a utilização do treinamento e da reciclagem como técnicas auxiliares às estratégias de Recursos Humanos, a presente pesquisa também constatou que os recursos investidos em treinamento ainda são pouco sistematizados pelas empresas.

A maior parte dos respondentes não sabe qual a proporção de gastos distribuídos entre salários e treinamentos, o mesmo

Tabela 3

\begin{tabular}{llc} 
Areas que Constituir-se-ão, Provavelmente, as Principais Necessidades de Treinamento nos Próximos 3 anos \\
\hline \multicolumn{1}{c}{ Áreas } & $\mathrm{F}$ & $\mathrm{F} \%$ \\
\hline Administração de negócios e estratégia & 194 & 12,22 \\
Gerenciamento de pessoal e supervisão & 187 & 11,78 \\
Computadores e novas tecnologias & 184 & 11,59 \\
Qualidade & 183 & 11,53 \\
Habilidades de atendimento ao cliente & 170 & 10,71 \\
Saúde e segurança e ambiente organizacional & 167 & 10,52 \\
Marketing e vendas & 151 & 9,51 \\
Mudanças de gerenciamento & 138 & 8,70 \\
Tecnologia de manufatura & 105 & 6,62 \\
Línguas & 101 & 6,36 \\
Outros & 7 & 0,44 \\
\hline Total & 1587 & 100,00
\end{tabular}


ocorrendo com relação ao número de dias de treinamento realizados para os funcionários. Entretanto, apesar deste desconhecimento, de modo geral, os participantes concordam que houve um aumento nos investimentos em treinamento nos últimos 3 anos, o que demonstra uma aproximação da realidade brasileira com as pesquisas internacionais, podendo-se pensar também que exista na realidade nacional uma maior conscientização quanto a importância do uso do treinamento.

Ao que parece o treinamento está sendo feito muito mais como uma atividade comum às rotinas de $\mathrm{RH}$ do que como parte de planejamento estratégico em prol do desenvolvimento organizacional, o que pode ocorrer pelo desconhecimento da amplitude deste campo de estudo e por conseguinte dos beneficios que o mesmo pode acarretar para a organização e para os colaboradores, dentro de uma visão menos isolada e mais sistêmica de treinamento.

Ainda que as organizações multinacionais demonstrem um maior enfoque do treinamento para os níveis gerenciais e administrativos e aquelas que possuem R.H. direcionem-se mais aos cargos técnicos e operacionais, na média geral, o número de dias despendidos com treinamento foi similar para todos os cargos avaliados, o que pode ser explicado em função dos novos desafios que vêm sendo enfrentados pelas organizações, como concorrência de mercado, programas de qualidade e melhorias contínuas, por exemplo, que forçam a empresa a melhorar o nível de qualificação de todos os trabalhadores. Outra explicação pode ser que a pouca atenção atribuída ao treino de alguns cargos esteja sendo mais claramente sentida pelas empresas, que buscam, portanto, ajustar-se às novas demandas uma vez que $\mathrm{o}$ envolvimento da equipe parece ser o caminho mais sólido para o enfrentamento das mudanças e manutenção do status de competitividade.

Quanto àidentificação das necessidades de treinamento, parece ser uma atividade que recebe maior atenção das organizações multinacionais e das que possuem o setor de RH. O diagnóstico dessas necessidades é crucial para o alcance dos objetivos organizacionais, pois destaca as carências dos trabalhadores e possibilita, por meio de um planejamento, o suprimento das mesmas. Entretanto, potencializar as competências é outra forma de estimular o funcionário a participar ativamente de seu processo de trabalho, o que facilitaria a percepção das suas atividades e do reconhecimento profissional.

No intuito de levantar tais necessidades, as organizações utilizam diferentes métodos e estão preocupadas em realizar o controle quanto à eficiência do treinamento ministrado, seja por instrumento formal de avaliação ou por feedback informal. É preciso lembrar que já é possível extrapolar esta visão mais comum de avaliação de treinamento, pois atualmente, há a preocupação com os preditores das condições de transferência dos conteúdos teóricos para a prática, que fazem parte do enfoque mais recente da avaliação, como mostra o estudo de SmithJentsch e colaboradores (2001).
O que se observa é que as empresas realizam a análise de necessidades, mas resta saber se o fazem de maneira adequada, o que pode ser objeto de investigações futuras.

Os planos de desenvolvimento de carreira tomam maior vulto nas empresas multinacionais, com mais de 500 funcionários e possuidoras de $\mathrm{RH}$, o mesmo ocorrendo com relação aos planos de sucessão. Vale notar que tal preocupação não foi apontada na maior parte das organizações paulistas e que não possuem R.H., o que caminha em direção contrária ao observado na literatura internacional.

Ao que parece, as empresas que possuem o Departamento de Recursos Humanos demonstram uma atenção maior às necessidades de treinamento e talvez o implemente com maior sucesso por contar com profissionais especializados para isto.

Já no que concerne às futuras necessidades de treinamento enfatizadas pelos sujeitos, estão as funções ligadas à gestão estratégica, informática e qualidade, o que reflete que as empresas estão sintonizadas com as tendências impostas pelo mercado de trabalho. É esperado que haja uma conscientização da necessidade de humanização do trabalho atrelada a tal conduta, reforçando a visão que hoje prevalece no mercado.

A relevância da temática sobre treinamento e desenvolvimento justifica a necessidade de continuidade dos esforços investigativos que cumpram a função de mapear aspectos que certamente merecem maior elucidação, o que pode ser considerado como uma das limitações do presente estudo. Assim fica como uma questão em aberto, saber o grau em que as empresas estão acompanhando a evolução teórica do assunto em suas práticas cotidianas e qual a eficácia das metodologias de avaliação que estão sendo utilizadas. Outra limitação a ser assinalada é que os dados foram obtidos apenas com empresas do Estado de São Paulo, o que pode não retratar a realidade de outras regiões brasileiras, onde a industrialização é bem menor.

Como demonstrado na presente revisão teórica, a literatura sobre treinamento evoluiu significativamente possibilitando uma prática respaldada em métodos científicos.

\section{Referências}

Abbad, G., Borges-Andrade, J. E., Sallorenzo, L. H., Gama, A. L. G. \& Morandini, D. (2001). Projeto instrucional, aprendizagem, satisfação com o treinamento e auto-avaliação de impacto do treinamento no trabalho. Psicologia: Organizações e Trabalho, 1, 129-161.

Albuquerque, L. G. (1992). Competitividade e Recursos Humanos. Trabalho apresentado no concurso de Professor Titular na Faculdade de Economia, Administração e Contabilidade da Universidade de São Paulo.

Bassi, L. J. \& Van Buren, M. E. (1999) Sharpening the leading edge. Disponivel no world wide web: http://www.astd.org/virtual_community/research/research _archive. btml, Data de acesso: 06/2003.

Borges-Andrade, J. E., Pereira, M. H. G., Puente-Palácios, K. E. \& Morandini D. C. (2002). Impacto individual e organizacional de treinamento: Uma análise com base num modelo de avaliação institucional e na teoria multinível. Psicologia: Organizações e Trabalho, 2, 117-146.

Brewster, C. \& Hegewisch, A. (1994). Human and practice in european buman resource management. Londres: Routledge. 
Bricchi, F. M. (1998). Como escolher o melhor treinamento. T \& D - Treinamento e Desenvolvimento, 67(6), 20-21.

Cannon-Bowers, J. A. \& Salas, E. (2001). Reflections on shared cognition. Journal of Organizational Behavior, 22, 195-202.

Carvalho, A. V. \& Nascimento, L. P. (1997). Administração de Recursos Humanos (Vol. 1). São Paulo: Pioneira.

Chiavenato, I. (1996). Como transformar o RH (de um centro de despesa) em um centro de lucro. São Paulo: Makron Books.

Colquitt, J. A., LePine, J. \& Noe, R. A. (2000). Toward an integrative theory of training motivation; a meta-analytic path analysis of 20 years of research. Journal of Applied Psychology, 85, 678-707.

Davis, K. \& Newstrom, J. W. (1992). Comportamento humano no trabalho: Uma abordagem psicológica (Vol. 1). São Paulo: Pioneira.

Ferreira, A. A. (1993). Avaliação dos resultados de um programa de desenvolvimento gerencial. Revista IMES, 10(29), 16-23.

Garay, A. B. S. (1997). As diferentes faces do processo de qualificação: Algumas dimensões esquecidas. Revista de Administração, 32(3), 52-61.

Georgenson, D. L. (1982). The problem of transfer calls for partnership. Training and Development Journal, 36(10), 75-78.

Gil, A. C. (1994). Administração de Recursos Humanos: Um enfoque profissional. São Paulo: Atlas.

Macian, L. M. (1987). Treinamento e desenvolvimento de Recursos Humanos. São Paulo: EPU.

Magalhães, M. L. \& Borges-Andrade, J. E. (2001). Auto e hetero-avaliação no diagnóstico de necessidades de treinamento. Estudos de Psicologia, 6(1), 33-50.

Marks, M. A., Sabella, M. J., Burke, C. S. \& Zaccaro, S. J. (2002). The impact of Cross-Training on team effectiveness. Journal of Applied Psychology, 87(1), 3-13.

Martocchio, J. J. (1998). Strategic compensation: A human resource management approach. Upper Saddle River, NJ: Prentice Hall.
Novelli, J. G. N. (1998). Avaliação em T \& D: Por que mudar? T \& D - Treinamento e Desenvolvimento, 65(6), 24-25.

Pastore, J. (1996). Flexibilização do mercado de trabalho e contratação coletiva. São Paulo: LTR.

Rabelo, F. M., Bresciani Filho, E. \& Oliveira, C. A. B. (1995). Treinamento e gestão da qualidade. Revista de Administração de Empresas, 35(3), 13-19.

Rocha, E. P. (1998). Educação profissional na empresa. T \& D - Treinamento e Desenvolvimento, 72(6),18-19.

Salas, E. \& Cannon-Bowers, J. A. (2001). The science os training: A decade on progress. Annual Review of Psychology, 52, 471-499.

Smith-Jentsch, K. A., Salas, E. \& Brannick, M. (2001). To transfer or not to transfer? Investigating the combined effects of trainee characteristics, team leader support, and team climate. Journal of Applied Psychology, 86, 279-292.

Taylor, P. J., Lamers, A., Vincent, M. P. \& O’Driscoll, M. P. (1998). The validity of immediate delayed self-reports in training evaluation: An exploratory field study. Applied Psychology: an International Review, 47, 459-479.

Towler, A. J. \& Dipboye, R. L. (2001). Effects of trainer expressiveness, organization, and trainee goal orientation on training outcomes. Journal of Applied Psychology, 86, 664-673.

Tannenbaum, S. I., Cannon-Bowers, J. A. \& Mathieu, J. E. (1993). Factors that influence training effectiveness: A conceptual model and longitudinal analysis. Rep. 93-011, Naval Train. Syst. Cent., Orlando, FL.

Sobre as autoras

Keli Cristina de Lara Campos é Docente da Universidade São Francisco, Itatiba, São Paulo e Doutoranda em Psicologia pela Universidade de São Paulo.

Ana Lúcia Jancovic Barduchi é Mestre em Psicologia pela Universidade de São Paulo. É Doutoranda em Educação pela Universidade Estadual de Campinas.

Daniela Giallucca Marques é Psicóloga.

Kátia Perez Ramos é Psicóloga e Mestre em Psicologia pela Pontifícia Universidade Católica de Campinas.

Lígia Angeli Dias dos Santos é Psicóloga organizacional.

Tatiana Janine Becker é Psicóloga. 